\title{
Compact Printable Inverted-M Shaped Chipless RFID Tag Using Dual-Polarized Excitation
}

\author{
Wazie M. Abdulkawi ${ }^{1, *(\mathbb{D}}$, Abdel-Fattah A. Sheta ${ }^{1}$, Khaled Issa ${ }^{2}$ and Saleh A. Alshebeili ${ }^{1,2}$ \\ 1 Department of Electrical Engineering, King Saud University, Riyadh 11421, Saudi Arabia; \\ asheta@ksu.edu.sa (A.-F.A.S.); dsaleh@ksu.edu.sa (S.A.A.) \\ 2 KACST-TIC in Radio Frequency and Photonics for the e-Society (RFTONICS), Electrical Engineering \\ Department, King Saud University, Riyadh 11421, Saudi Arabia; kissa@ksu.edu.sa \\ * Correspondence: walkadri@ksu.edu.sa; Tel.: +966-11-46-76796
}

Received: 24 April 2019; Accepted: 22 May 2019; Published: 25 May 2019

\begin{abstract}
A novel and compact dual-polarized (DP) chipless radio-frequency identification (RFID) tag is presented in this paper. This tag can read both vertical and horizontal orientations within its frequency band, which improves the robustness and detection capability of the RFID system. The proposed tag makes use of the slot length variation encoding technique to improve the encoding capacity. This technique can duplicate the encoding capacity, thereby reducing the overall tag size by almost $50 \%$. In particular, the proposed tag has an encoding capacity of 20 bits in the $3-8 \mathrm{GHz}$ frequency band and achieves data density of around $15.15 \mathrm{bits} / \mathrm{cm}^{2}$. Three prototypes are fabricated and tested outside an anechoic chamber. Furthermore, one tag is tested at different distances $(10 \mathrm{~cm}$, $30 \mathrm{~cm}$, and $60 \mathrm{~cm}$ ) from the reader and the measured results are compared. The simulated and measured results are in reasonable agreement, with acceptable shifts at some frequencies due to fabrication and experimental errors.
\end{abstract}

Keywords: chipless RFID; frequency selective surfaces (FSSs); dual-polarized; length variation; internet of things (IoT)

\section{Introduction}

Radio frequency identification technology (RFID) is a wireless system that uses radio frequency electromagnetic fields to exchange data between tags attached to an object and a reader device, which sends interrogator signals for identification. The conventional RFID tag contains an integrated circuit (IC), which is a main source of the increase in its cost. A new RFID structure has been investigated in the last few years. This new structure does not contain a silicon chip and it is called chipless RFID. Different methods have been reported in recent years for data encoding in chipless RFID tags. Generally, these encoding methods can be classified in various domains, as in time, frequency, and phase. In addition, hybrid-domain encoding techniques can improve the tag code detection [1]. In time domain (TD) based tags, the RFID reader interrogates the tag with a sequence of pulses. Then, the tag code can be estimated from the echoes reflected from a set of reflectors implemented on the tag attached to an object. In other words, existence or absence of these echoes and their time positions are used to identify the tag code [2,3]. In frequency domain (FD) based tags, the RFID reader interrogates the tag with an RF signal and then the tag retransmits the frequency signature to the reader. Each data bit represents the presence or absence of a resonant frequency in the operating spectrum [4-7]. Phase domain (PD) based encoding technique was presented in [8]. In that work, three square microstrip patch antennas loaded with three open circuit stubs are suggested to encode three bits. Varying the length of the stub alters the phase of the backscattered signal. In the hybrid domain (HD) encoding techniques, more than one domain is used $[9,10]$. However, as mentioned in [3], for significant numbers of bits, HD 
techniques still require very high spectral bandwidth and the resultant configuration, in this case, will not be matched for low-cost readers.

Back to frequency domain, chipless RFID tags can be operated either in retransmission-mode or in backscattered-mode. Retransmission based chipless RFID tags use multi-resonator circuits and two UWB antennas for data transmission and reception [11,12]. The retransmission-based tags suffer due to their large size and complex structure [13].

In contrast to retransmission-mode, backscattering based tags consists only of resonating elements (scatterers) where no separate antennas are required [14-16]. Therefore, significant area reduction can be achieved. In addition to area saving, increasing data density is still a real challenge in the chipless RFID systems. In literature, the number of chipless RFID tags is proposed to enhance the data capacity and the detection methods. For example, slot length variation can be exploited in order to double the data capacity in the same frequency band [6]. In [17,18], Multiple I- and U-slots dual polarized resonators etched on a rectangular patch are proposed in the frequency range 6-13 GHz. The slot resonators (I or U) are reused in both vertical and horizontal polarizations. Recently, some dual polarized structures have been investigated, such as the L-shaped strips [19] and square loop [20]. Polarization insensitive structures, such as the triangular loops [21], circular loops [22], and multiple L-strips resonators [23], have also been studied. The advantage of these structures is that the tag data can be read from any orientation by the reader antennas.

This paper presents a 20 bits compact very high density chipless RFID tag by using inverted M-shaped multiple slots resonators. This compact tag uses the dual polarized technique to improve the detection method, and slot length variation to double the encoding capacity in the same frequency band. A tag of 20 bits encoding capacity is designed and analyzed. The proposed tag is simulated using a computer simulation technology (CST) EM simulator as an infinite structure. This paper is organized as follows: Section 2 presents the proposed chipless RFID tag. Section 3 presents the simulation results of some Inverted-M chipless RFID tags. In Section 5, three prototypes of the proposed tag are experimentally validated. Finally, concluding remarks are given in Section 6.

\section{Proposed Chipless RFID Tag}

Figure 1 shows the proposed DP chipless RFID tag. This tag consists of a conductive rectangular patch overloaded with sets of inverted M slots. The resonance frequency of a half wave slot resonator can be calculated approximately using the expression [24]:

$$
f=\frac{c}{2 l} \sqrt{\frac{2}{1+\varepsilon_{r}}}
$$

where $l$ is the total physical slot length of the M-shaped resonator, $\mathrm{c}$ is the speed of light, and $\varepsilon_{r}$ is the permittivity of the substrate. In this paper, the tag is designed using Rogers RT5880 substrate having thickness $(h=0.256 \mathrm{~mm})$ and permittivity $\left(\varepsilon_{r}=2.2\right)$.

As shown in Figure 1, $l$ and $w$ are the length and width of the rectangular patch. $s_{x}$ is the separation distance between the vertical slots, while $s_{y}$ is approximately defined as the separation distance between the slanted slots, and $w_{s}$ is the width of all slots. Each slot resonator can be positioned in either the active or the passive mode of operation. A diagram of ten slot resonators in the active mode is presented in Figure 2a. The slot resonators can be made inactive by adding five short circuits at different parts of the resonator, as shown in Figure $2 b$. 


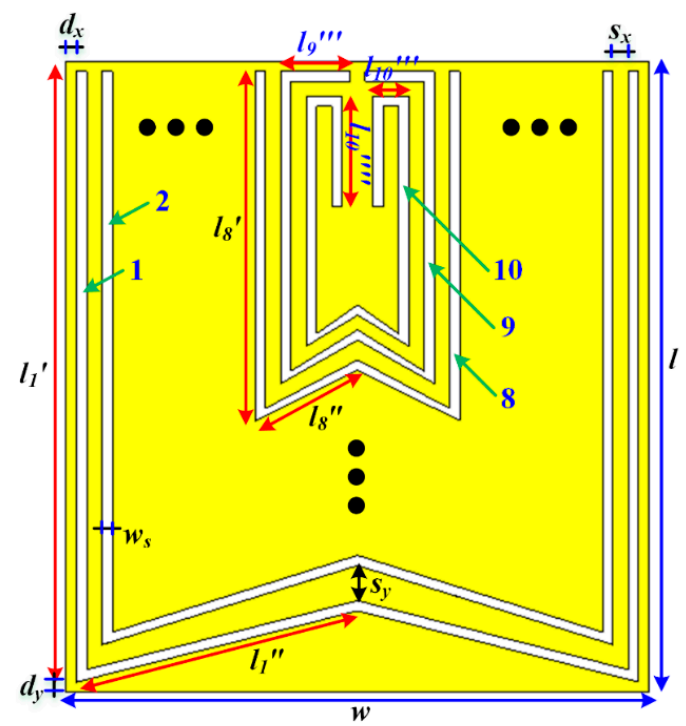

Figure 1. Geometry of the tag.

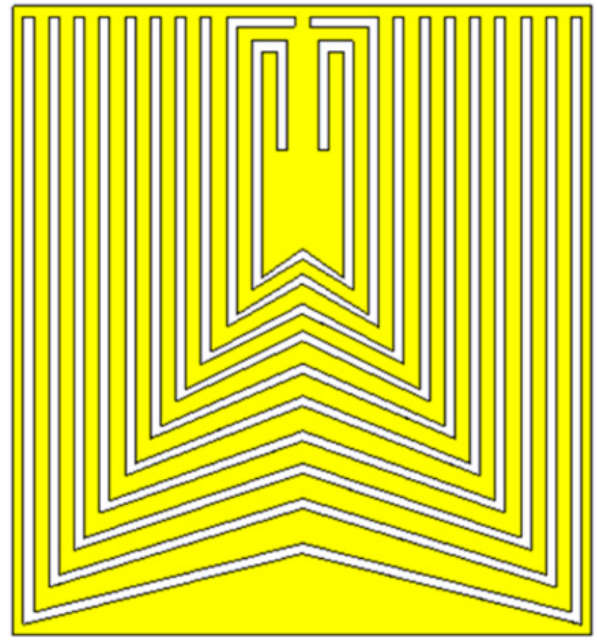

(a)

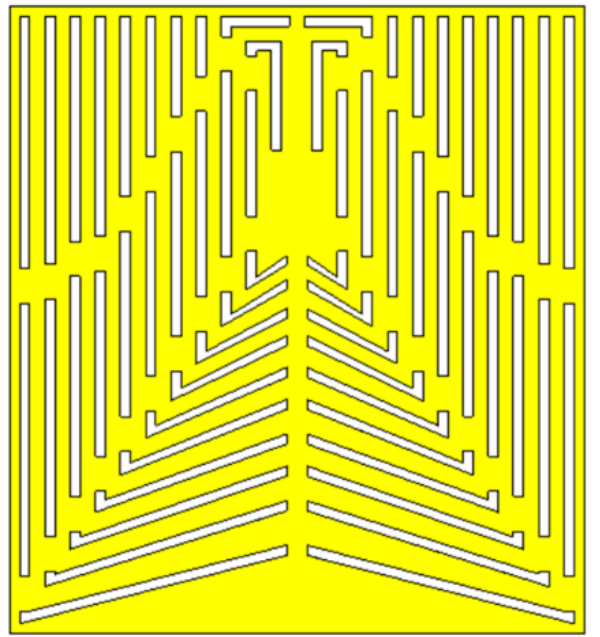

(b)

Figure 2. Ten inverted-M chipless RFID tags (a) active mode and (b) passive mode.

The main physical dimensions of the tag shown in Figure 1 are listed in Table 1 . All slot resonators have the same separation distances between the vertical slots $\left(s_{x}\right)$ and different separation distances between the slanted slots $\left(s_{y}\right)$ as indicated in Table 2.

Table 1. Main design parameters.

\begin{tabular}{ccccccc}
\hline Parameter & $\mathbf{1}$ & $\mathbf{W}$ & $\mathbf{d}_{\mathbf{x}}$ & $\mathbf{d}_{\mathbf{y}}$ & $\mathbf{w}_{\mathbf{s}}$ & $\mathbf{s}_{\mathbf{x}}$ \\
\hline Value $(\mathrm{mm})$ & 12.4 & 11.4 & 0.2 & 0.2 & 0.2 & 0.3 \\
\hline
\end{tabular}

Table 2. Separation distances between the slanted slots.

\begin{tabular}{cccccccccc}
\hline Parameter & $\mathbf{s}_{\mathbf{y} 1}$ & $\mathbf{s}_{\mathbf{y} 2}$ & $\mathbf{s}_{\mathbf{y} 3}$ & $\mathbf{s}_{\mathbf{y} 4}$ & $\mathbf{s}_{\mathbf{y} 5}$ & $\mathbf{s}_{\mathbf{y} 6}$ & $\mathbf{s}_{\mathbf{y} 7}$ & $\mathbf{s}_{\mathbf{y} 8}$ & $\mathbf{s}_{\mathbf{y} 9}$ \\
\hline Value $(\mathrm{mm})$ & 0.69 & 0.49 & 0.44 & 0.49 & 0.44 & 0.44 & 0.34 & 0.39 & 0.29 \\
\hline
\end{tabular}


The length of each slot resonator is determined by the following formula $(i=1,2, \ldots, 9,10)$ :

$$
l_{i}=\frac{c}{2 f_{i}} \sqrt{\frac{2}{1+\varepsilon_{r}}}
$$

$l_{i}$ represents the total length of the $i$ th slot resonator and can be written according to the notation in Figure 1 as:

$$
\begin{gathered}
l_{i}=2\left(l_{i}{ }^{\prime}+l_{i}{ }^{\prime \prime}\right)(i=1,2, \ldots, 7,8), \\
l_{9}=2\left(l_{9}{ }^{\prime}+l_{9}^{\prime \prime}+l_{9}^{\prime \prime \prime}\right), \\
l_{10}=2\left(l_{10}{ }^{\prime}+l_{10}{ }^{\prime \prime}+l_{10}{ }^{\prime \prime \prime}+l_{10}{ }^{\prime \prime \prime \prime}\right) .
\end{gathered}
$$

The designed tag is optimized to produce deep notches at the desired frequencies in the operating frequency range from $3 \mathrm{GHz}$ to $8 \mathrm{GHz}$. Initially, one novel inverted-M-shaped slot resonator is designed to obtain one notch in the desired frequency range. Afterwards, by optimization, inverted-M resonators are added to obtain multiple notches in the mentioned frequency range. By this process, the number of notches can be controlled by adding or removing the inverted-M slot resonators. In our case, ten optimized inverted-M slots were utilized to obtain ten notches. To ensure the compactness of the structure, the available area was utilized efficiently by twisting the last two slot resonators. The length of the slot resonator decreases as the value of the resonance frequency increases. The resonance frequencies can be calculated using Equation (1), depending on the physical dimensions of each slot.

Slot number 1 gives the lowest resonant frequency because of its longest length and as it corresponds to the most significant bit (MSB). By contrast, the least significant bit (LSB) is related to the smallest slot length (slot number 10) that resonates at maximum frequency. The reflection coefficients are computed when the tag is excited with vertically and horizontally polarized waves. These waves are incident normal to the chipless RFID tag surface. When the plane wave excites the tag, a much higher surface current is induced around the slots at its resonant frequency. These orthogonal polarities are utilized to double the encoding capacity $[25,26]$.

Therefore, the proposed structure shows a frequency-selective behavior with deep notches at all resonant frequencies. These notches (resonance frequencies) can be controlled by adding short circuits in each slot. In the developed tag, ten bits are achieved using ten vertically polarized slots and another ten bits are accomplished from the ten horizontally polarized slots on the conductive rectangular patch. Logically, the active slot resonator represents logic 1 and the passive resonator represents logic 0 . Therefore, the designed tag in Figure 2a denotes logic (1111111111) and the tag in Figure $2 \mathrm{~b}$ indicates logic (0000000000).

\section{Simulation Results}

The proposed tag is designed and simulated using CST Microwave Studio. Backscattered chipless RFID tags can be analyzed either using monostatic or bistatic reader system. Bistatic systems use two antennas-one for transmitting and one for receiving. However, monostatic systems use a single antenna for both interrogating and reading purposes, and therefore they are usually less expensive than bistatic systems.

The simulation setup of the DP chipless RFID tag is shown in Figure 3. The tag can be excited by either a vertically or horizontally polarized plane wave. In each case, the backscatter field is received and the frequency signature of the tag can be identified from the reflection coefficient response $S_{11}$. 


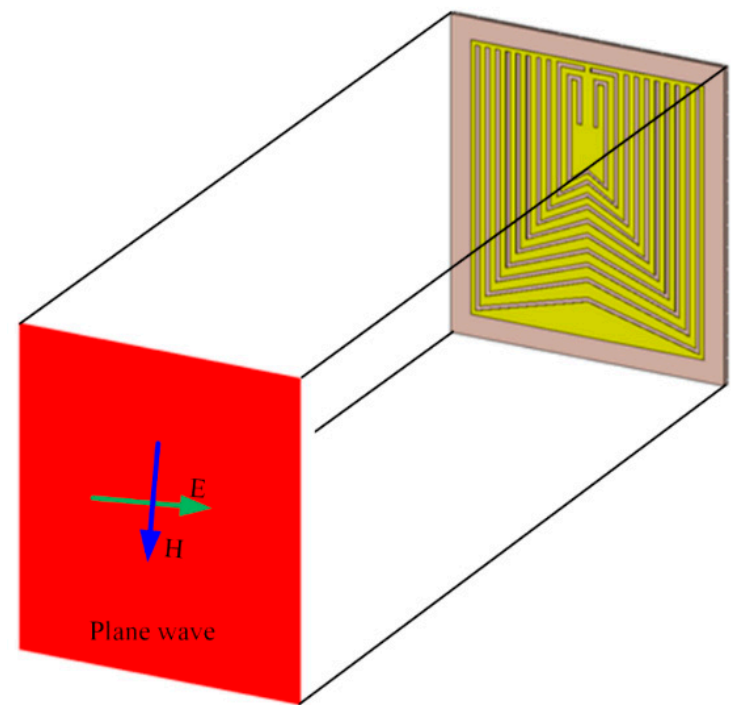

Figure 3. Simulation setup for the proposed tag.

To validate the concept, four different passive tags are designed and simulated. The proposed tag with four different bit configurations 1111111111, 0000000000, 0101010101, and 1010101010 is shown in Figure 2a,b and Figure 4a,b, respectively.

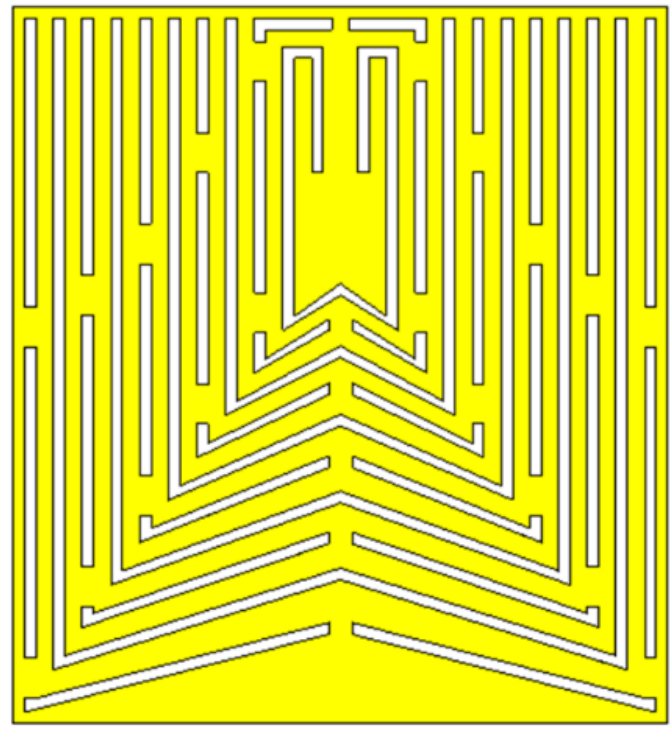

(a)

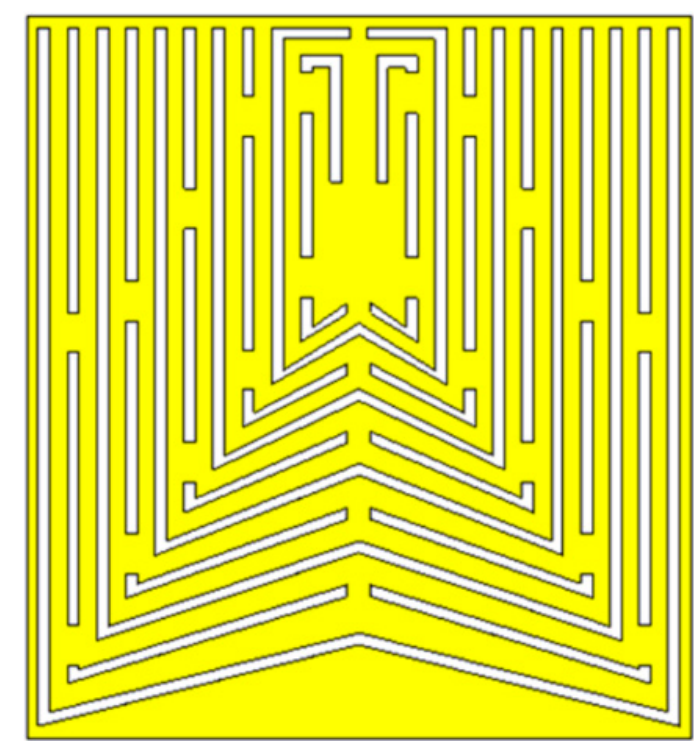

(b)

Figure 4. Designed tag with two different bit combinations: (a) “0101010101” and (b) “1010101010”.

Figure 5 shows the reflection coefficients $S_{11}$ of the designed chipless RFID tag structures that have all ones (1111111111) and all zeros (0000000000) for both vertically and horizontally plane waves. Table 3 illustrates the total length and the corresponding frequency of each slot resonator (using Equation (1)). Twenty resonances are observed in the backscattered signal from the designed tag of the all-ones state. Ten frequency signatures are related to the vertically polarized wave and ten signatures from the horizontally polarized wave. These resonance frequencies are listed in Table 3, where we observe that the maximum difference between the resonance frequencies for both polarizations is approximately $104 \mathrm{MHz}$ and the minimum difference is approximately $8 \mathrm{MHz}$. 


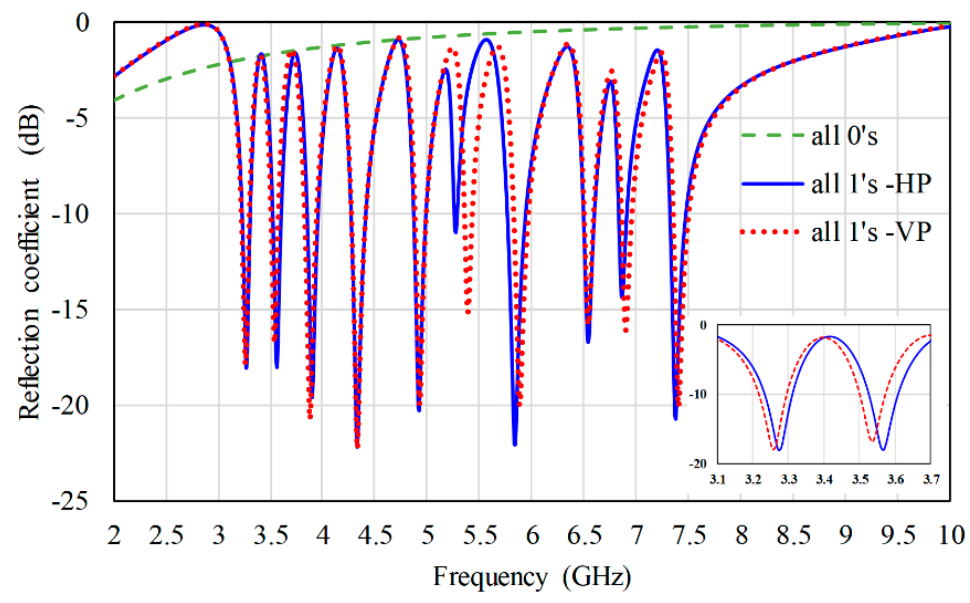

Figure 5. Amplitude reflection coefficients of the vertical (VP) and horizontal (HP) polarizations for states "1111111111" and “0000000000".

On the other hand, Figures 6 and 7 show the frequency responses of two other tags with alternating ones and zeros: (1010101010) and (0101010101), respectively. These responses are achieved under vertical and horizontal plane-wave excitations. The shift in frequency between the two responses is necessary to achieve a very sharp peak-to-peak difference between the two curves [14]. Figure 8 shows the difference in dBs between the vertical and horizontal polarized $S_{11}$ of Figure 5 (code: 1111111111). Additionally, the difference between the vertical and horizontal polarized $S_{11}$ for the codes 1010101010 and 0101010101 is reported in Figures 9 and 10, respectively. Sharp peak-to-peak response is observed for all-ones codes.

Table 3. Physical lengths and the corresponding resonance frequencies of the slot resonators.

\begin{tabular}{cccccc}
\hline \multicolumn{2}{c}{ Total Length } & \multirow{2}{*}{$\begin{array}{c}\text { Calculated Resonant } \\
\text { Frequency }(\mathbf{G H z})\end{array}$} & \multicolumn{2}{c}{$\begin{array}{c}\text { Simulated Resonant Frequency } \\
\mathbf{( G H z )}\end{array}$} & \multirow{2}{*}{$\boldsymbol{\Delta}(\mathbf{M H z})$} \\
\cline { 1 - 1 } Parameter & Value $(\mathbf{m m})$ & & Vertical & Horizontal & \\
\hline$l_{1}$ & 35.36 & 3.351 & 3.256 & 3.272 & 16 \\
\hline$l_{2}$ & 33.02 & 3.589 & 3.536 & 3.568 & 32 \\
\hline$l_{3}$ & 30.56 & 3.878 & 3.872 & 3.904 & 32 \\
\hline$l_{4}$ & 28.08 & 4.220 & 4.328 & 4.336 & 8 \\
\hline$l_{5}$ & 25.66 & 4.618 & 4.928 & 4.936 & 8 \\
\hline$l_{6}$ & 23.18 & 5.112 & 5.384 & 5.280 & 104 \\
\hline$l_{7}$ & 20.74 & 5.714 & 5.880 & 5.848 & 32 \\
\hline$l_{8}$ & 18.18 & 6.518 & 6.536 & 6.544 & 8 \\
\hline$l_{9}$ & 17.62 & 6.726 & 6.896 & 6.872 & 24 \\
\hline$l_{10}$ & 16.7 & 7.270 & 7.400 & 7.384 & 16 \\
\hline
\end{tabular}




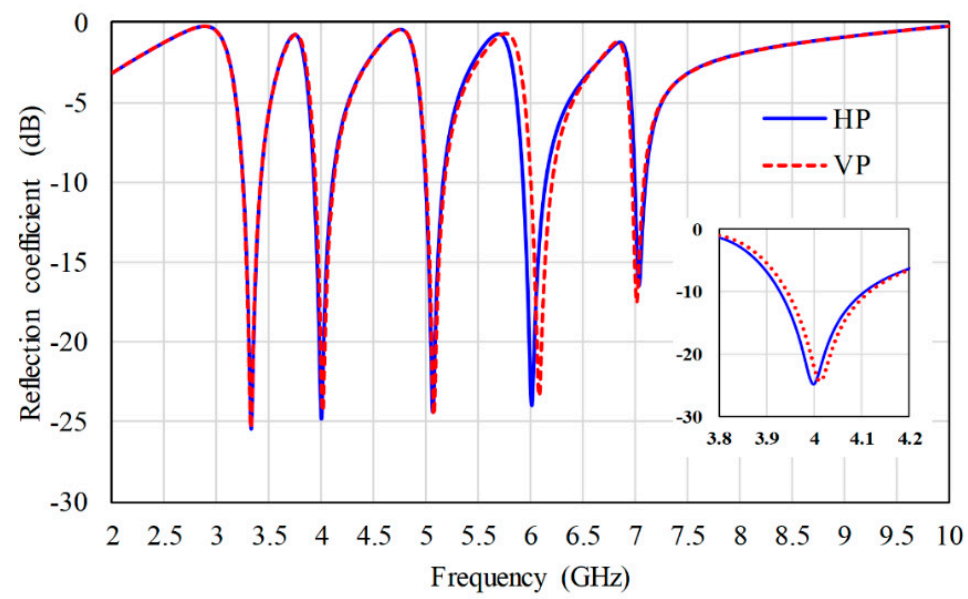

Figure 6. Vertically (VP) and horizontally (HP) polarized $S_{11}$ of the proposed tag with state "1010101010".

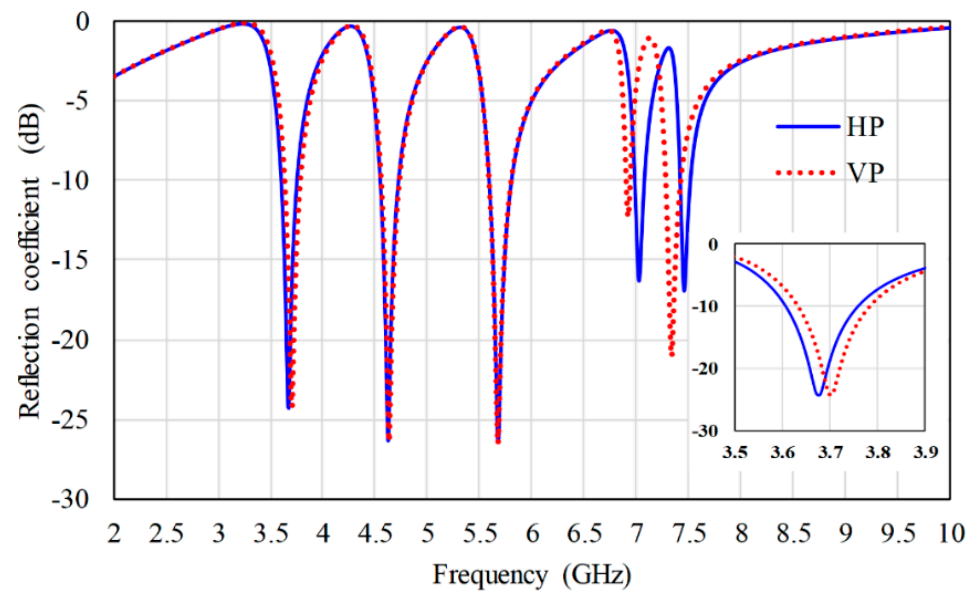

Figure 7. Vertically (VP) and horizontally (HP) polarized $S_{11}$ for code “0101010101”.

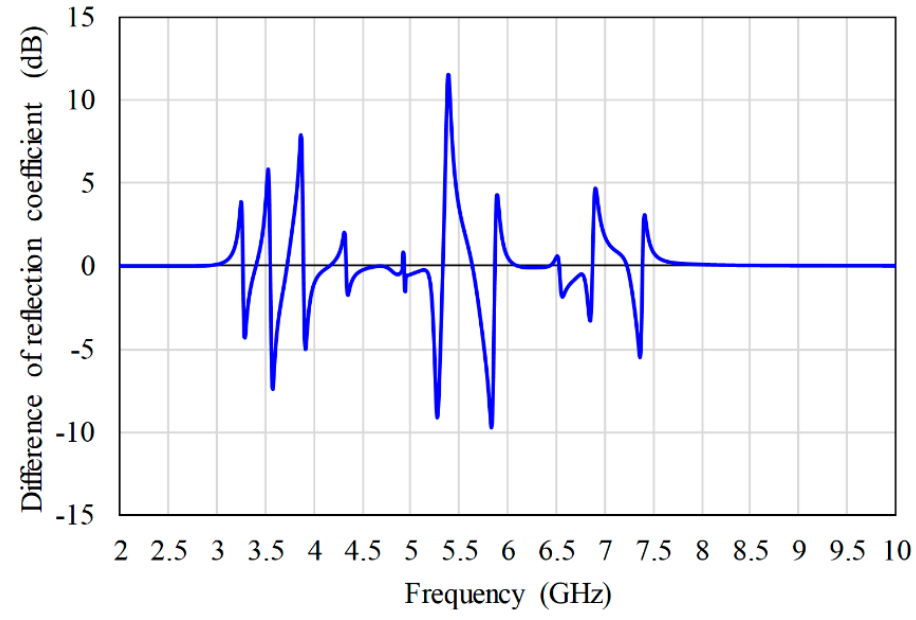

Figure 8. Amplitude difference between vertically and horizontally polarized $\mathrm{S}_{11}$ for code "1111111111". 


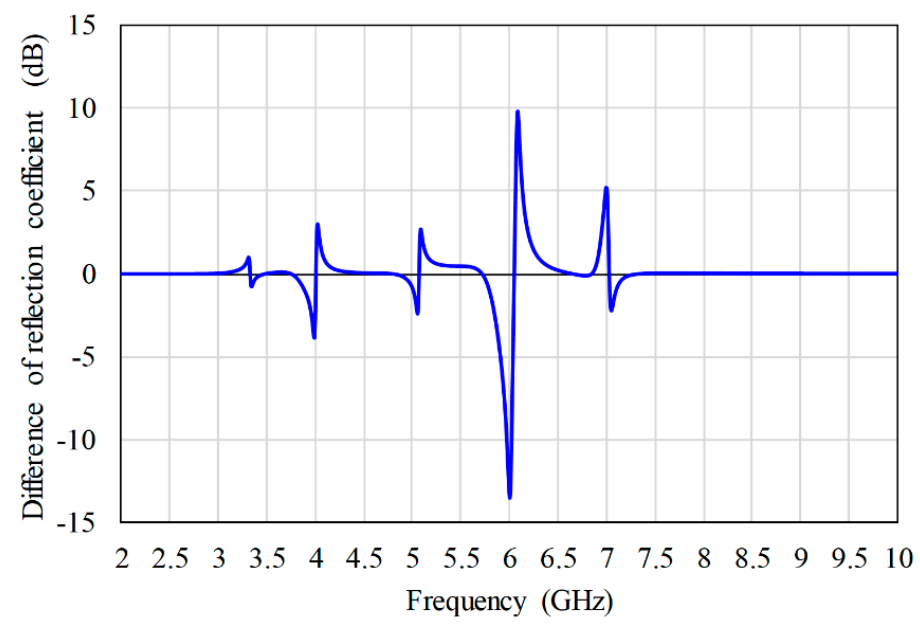

Figure 9. Amplitude difference between vertically and horizontally polarized $S_{11}$ for code "1010101010".

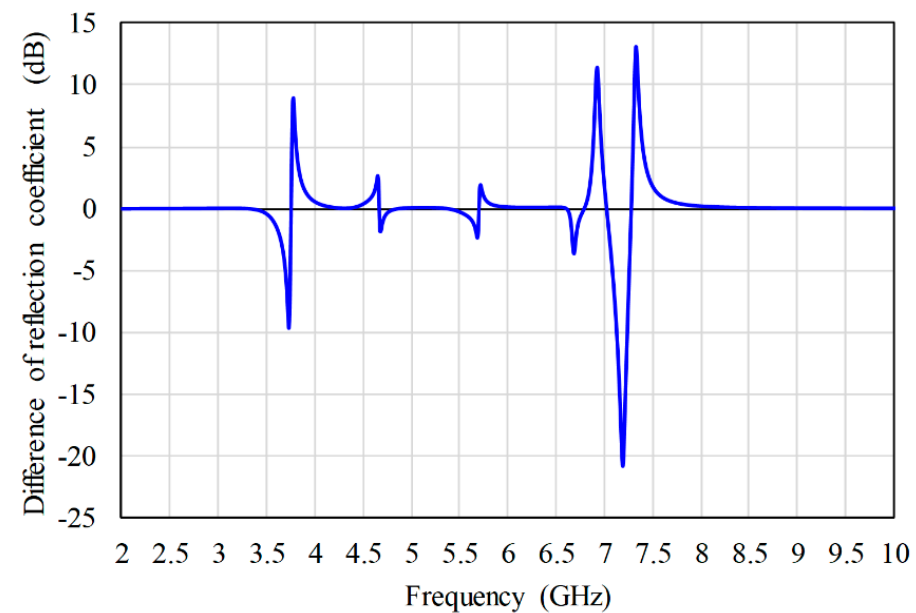

Figure 10. Amplitude difference between vertically and horizontally polarized $S_{11}$ for code “0101010101”.

\section{The 20-Bit Dual Polarized Tag}

The resonance frequency of the slotted line is inversely proportional to the slot length. Thus, increase in the slot length will decrease its resonance frequency and vice versa. Therefore, each resonator can be represented by one of the four possible states: $00,10,01$, and 11 . The first state, 00 , is obtained when the resonator is short-circuited. No resonance can be observed in the band of operation. The second state (11) is related to resonator's length $l_{i}$ and subsequently resonance frequency $f_{i}$. In the third case (10), the length of the slot " $i$ " is slightly increased. This slight modification results in a shift in the resonance frequency from $f_{i}$ to $f_{i}{ }^{-}$. A slight decrease in slot " $i$ " length will result in a shift in the resonance frequency from $f_{i}$ to $f_{i}{ }^{-}$. This is the fourth state (01). Therefore, the encoding capacity (bits) and encoding density (bits $/ \mathrm{cm}^{2}$ ) will be doubled within the fixed frequency band. Table 4 illustrates the all-possible states. The simulated $S_{11}$ for these cases are illustrated in Figure 11 for all 10 active resonators. Table 5 figures out the corresponding frequencies for the proposed tag with increasing and decreasing slot lengths. As listed in Table 5, the maximum difference between the resonance frequencies for both variations is approximately $280 \mathrm{MHz}$ and the minimum difference is approximately $40 \mathrm{MHz}$. 
Table 4. Possible states for a single resonator.

\begin{tabular}{|c|c|c|c|}
\hline Configuration & Possible States & Resonance Frequency & Code \\
\hline Resonator with short circuits & First state & No resonance & 00 \\
\hline Normal resonator & Second state & $f$ & 11 \\
\hline $\begin{array}{l}\text { The slot length } l \text { increased by } \\
\text { factor of } \Delta L^{+}\end{array}$ & Third state & $f^{-}$ & 10 \\
\hline $\begin{array}{l}\text { The slot length } l \text { decreased by } \\
\text { factor of } \Delta L^{-}\end{array}$ & Fourth state & $f^{+}$ & 01 \\
\hline
\end{tabular}

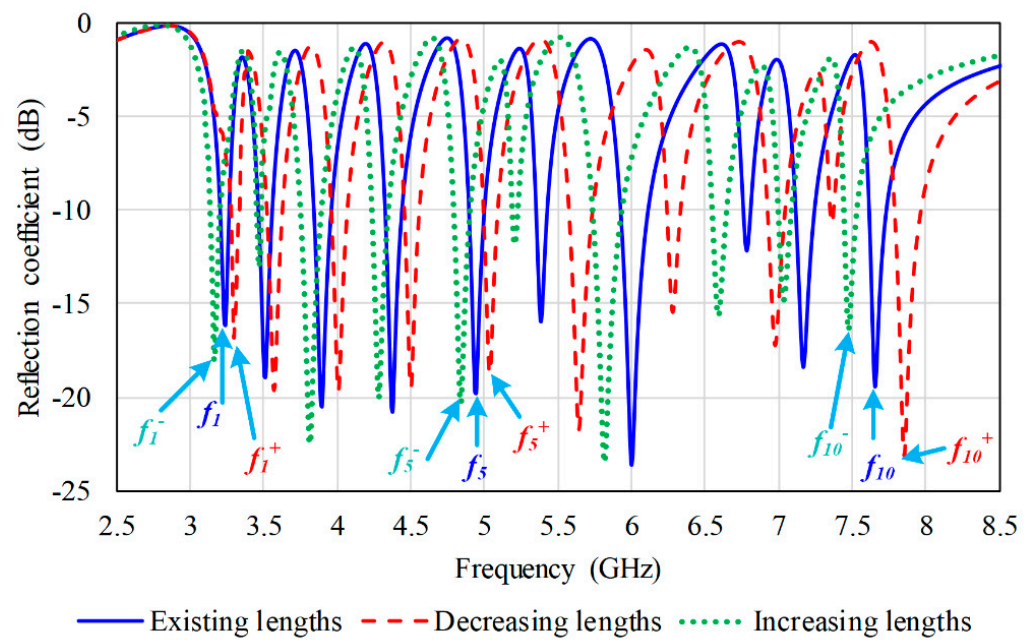

Figure 11. Two simulated $S_{11}$ for the proposed tag with length variations.

Table 5. The corresponding resonance frequencies of the slot variation resonators.

\begin{tabular}{|c|c|c|c|c|c|c|c|}
\hline \multicolumn{2}{|c|}{ Existing Frequencies } & \multicolumn{2}{|c|}{ Decreasing Frequencies } & \multicolumn{2}{|c|}{ Increasing Frequencies } & \multirow{2}{*}{$\Delta^{-}(\mathrm{MHz})$} & \multirow{2}{*}{$\Delta^{+}(\mathrm{MHz})$} \\
\hline Parameter & Value (GHz) & Parameter & Value (GHz) & Parameter & Value (GHz) & & \\
\hline$f_{1}$ & 3.24 & $f_{1}^{-}$ & 3.168 & $f_{1}^{+}$ & 3.296 & 72 & 56 \\
\hline$f_{2}$ & 3.512 & $f_{2}^{-}$ & 3.472 & $f_{2}{ }^{+}$ & 3.568 & 40 & 56 \\
\hline$f_{3}$ & 3.896 & $f_{3}^{-}$ & 3.816 & $f_{3}+$ & 4.008 & 80 & 112 \\
\hline$f_{4}$ & 4.376 & $f_{4}^{-}$ & 4.288 & $f_{4}^{+}$ & 4.496 & 88 & 120 \\
\hline$f_{5}$ & 4.944 & $f_{5}^{-}$ & 4.848 & $f_{5}^{+}$ & 5.04 & 96 & 96 \\
\hline$f_{6}$ & 5.384 & $f_{6}{ }^{-}$ & 5.216 & $f_{6}+$ & 5.64 & 168 & 256 \\
\hline$f_{7}$ & 6.0 & $f_{7}^{-}$ & 5.824 & $f_{7}^{+}$ & 6.28 & 176 & 280 \\
\hline$f_{8}$ & 6.784 & $f_{8}^{-}$ & 6.6 & $f_{8}{ }^{+}$ & 6.976 & 184 & 192 \\
\hline$f_{9}$ & 7.168 & $f_{9}^{-}$ & 7.04 & $f_{9}^{+}$ & 7.36 & 128 & 192 \\
\hline$f_{10}$ & 7.656 & $f_{10^{-}}$ & 7.472 & $f_{10}{ }^{+}$ & 7.856 & 184 & 200 \\
\hline
\end{tabular}

\section{Experimental Validation}

In order to validate the proposed concept, three prototypes were fabricated and measured in a normal environment. The ID codes of these prototypes are 11111111111111111111, 11001100110011001100, and 00110011001100110011. The simulated reflection coefficients were the results of an infinite array of the proposed tag. However, the manufactured tags were reduced to a finite $3 \times 3$ array of unit cells in order to decrease the physical size as much as possible. The physical dimensions of the $3 \times 3$ array of unit cells were $37.6 \times 34.6 \mathrm{~mm}^{2}$, as illustrated in Figure 12. The three fabricated tags, shown in Figures 12 and 13, were measured in both vertically and horizontally polarized orientations using the measurement setup depicted in Figure 14. The frequency responses of the 
fabricated tags were measured using the two-port PNA-X microwave network analyzer (N5242A) and a broadband horn antenna operating from 1 to $18 \mathrm{GHz}$.

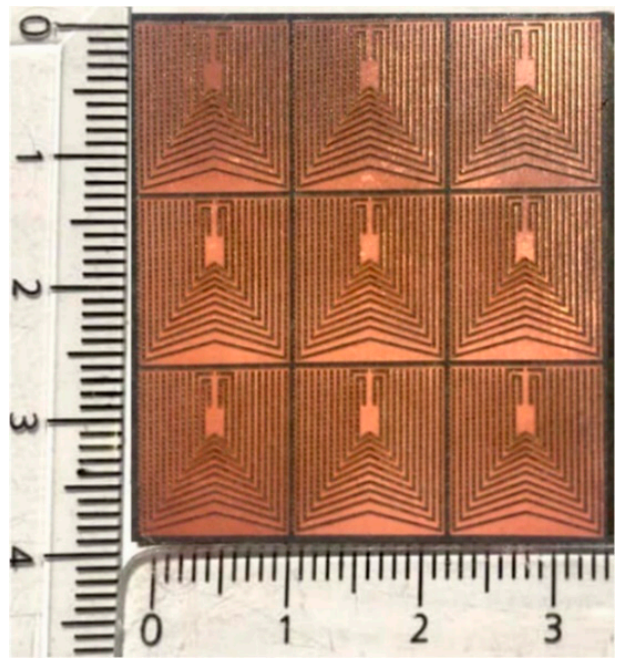

Figure 12. Proposed tag with nine unit cells (ID: 11111111111111111111).

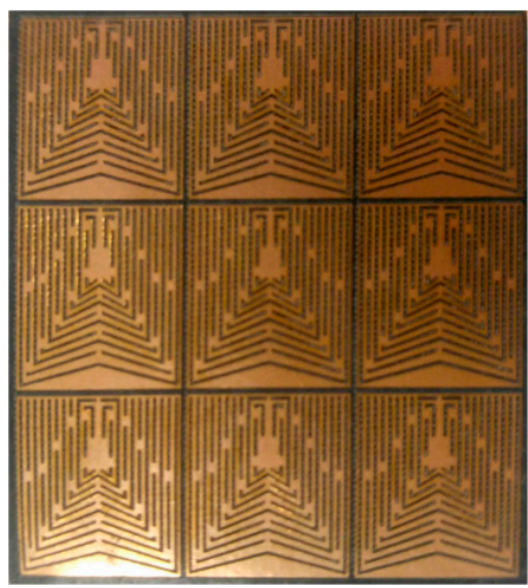

(a)

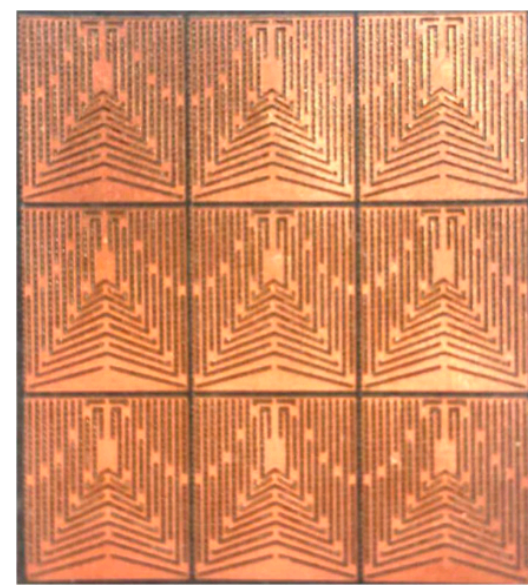

(b)

Figure 13. Fabricated images of the proposed tag with two different bit combinations: (a) 11001100110011001100 and (b) 00110011001100110011.
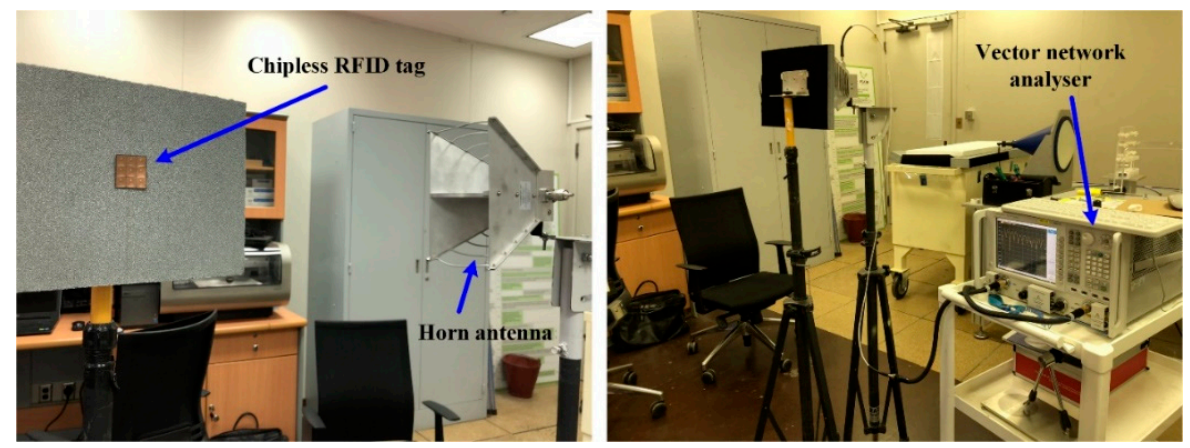

Figure 14. Measurement setup outside the anechoic chamber.

The measurements are performed in a normal environment (outside an anechoic chamber). In this case, the back scattered signal received by the reader (horn antenna connected to the network analyzer) consists of the reflected signal from the horn antenna impedance mismatch, the required 
frequency signature signal from the tag, the reflected signal from the metallic structure of the tag, the clutter noise from the surroundings, and the white noise. The effect of the horn impedance mismatch and the clutter noise can be approximately removed by an appropriate calibration technique $[23,27,28]$. In this work, the calibration method is employed by subtracting the reflection coefficient $\left(\mathrm{S}_{11}\right)$ of the measurement system without a tag from the reflection coefficient $\left(\mathrm{S}_{11}\right)$ with a tag.

The simulated and measured results for the fabricated prototypes are compared in Figure 15 (horizontal orientation) and Figure 16 (vertical orientation). The tag was positioned at a distance of $10 \mathrm{~cm}$ from the horn antenna (chipless RFID reader). Figure 15a shows the presence of ten nulls (code: 11111111111111111111) for horizontal polarization over the desired frequency band. The measured results are in reasonable agreement with the simulated ones, with slight shifts at some frequencies. This frequency shift may be attributed to material parameters variations and fabrication accuracy. Therefore, the frequency shifts of a given slot in the various states $(01,10$, and 11$)$ occur approximately in the same way. In this case, calibration using some samples (prototypes) could be used in practical applications to reduce errors due to any frequency shift.

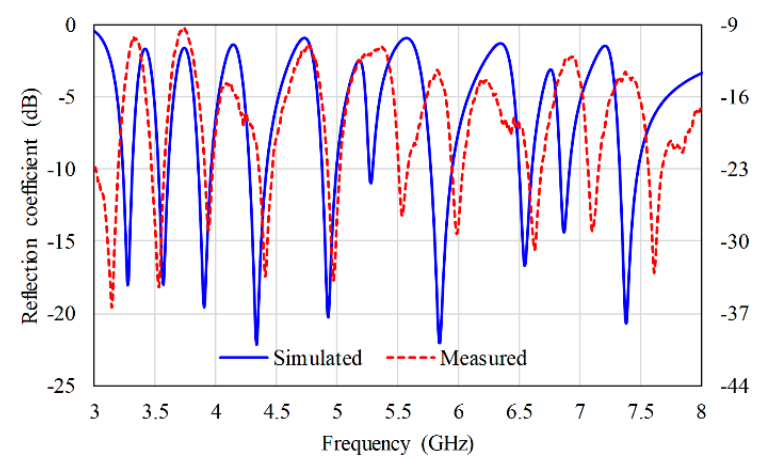

(a)

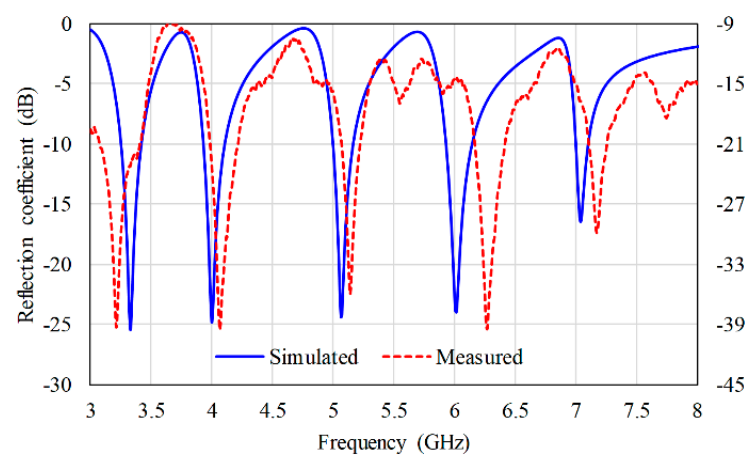

(b)

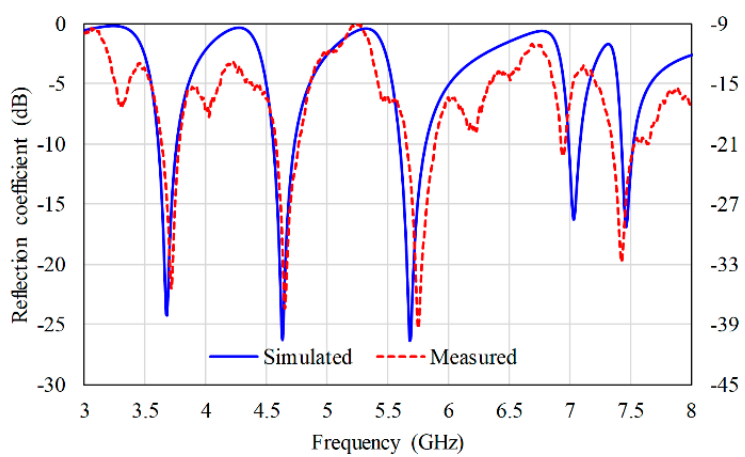

(c)

Figure 15. Simulated and measured $S_{11}$ under horizontal polarization for $10 \mathrm{~cm}$ distance from the RFID reader: (a) ID: 11111111111111111111, (b) ID: 11001100110011001100 , and (c) ID: 00110011001100110011. 


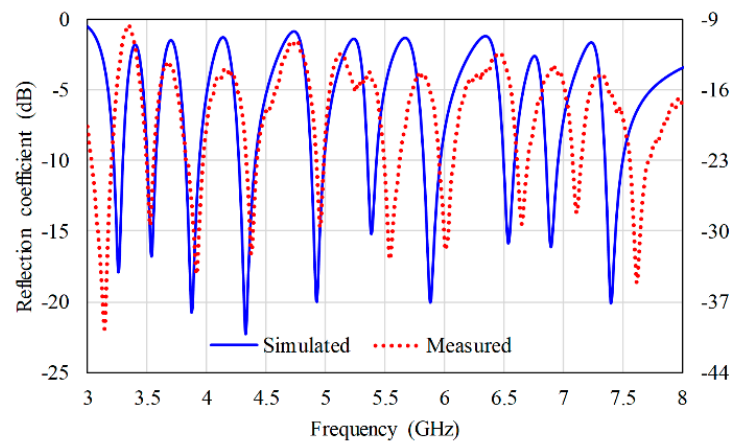

(a)

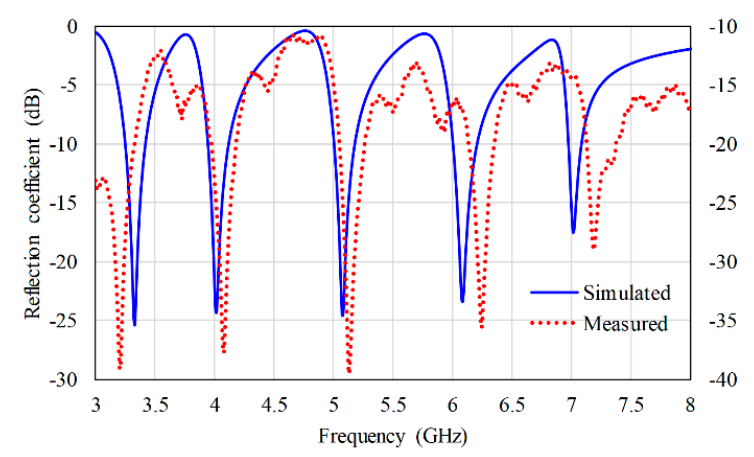

(b)

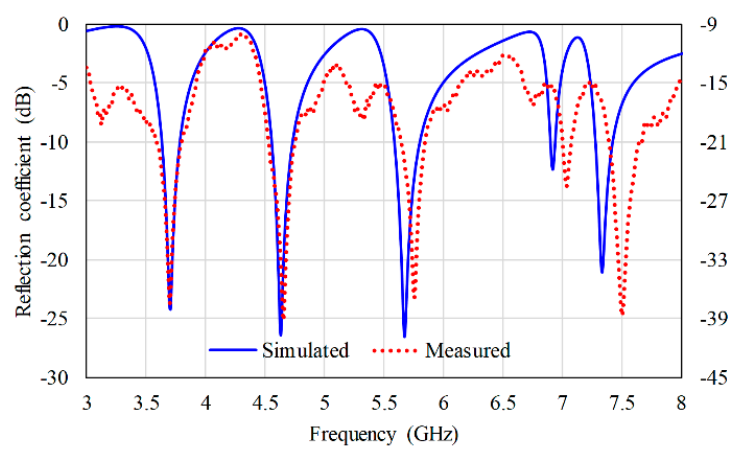

(c)

Figure 16. Simulated and measured $S_{11}$ under vertical polarization for $10 \mathrm{~cm}$ distance from the RFID reader: (a) ID: 11111111111111111111, (b) ID: 11001100110011001100 , and (c) ID: 00110011001100110011.

For further validation, the all-ones tag was tested for different distances $(10 \mathrm{~cm}, 30 \mathrm{~cm}$, and $60 \mathrm{~cm})$. The measured results are compared in Figure 17. The effectiveness and accuracy of the tag can be seen from Figure 17, as the tag is distinguishable even up to a distance of $60 \mathrm{~cm}$. A comparison of the designed tag with some of the existing chipless RFID tags is reported in Table 6. According to our knowledge and the comparison in Table 6, the proposed tag is the best in terms of coding density (bits/(GHz: $\left.\left.\mathrm{cm}^{2}\right)\right)$ and number of bits in backscatter technique.

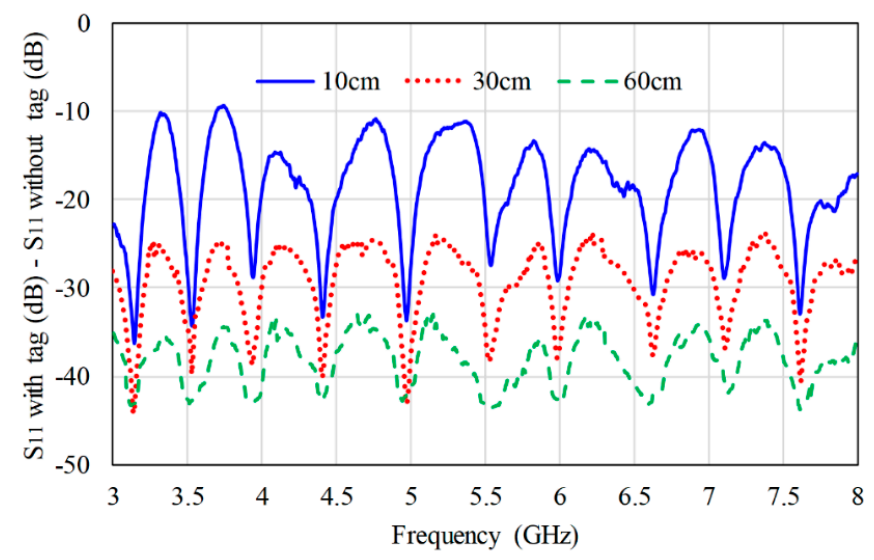

Figure 17. Measured responses of the nine unit cells at different distances. 
Table 6. Comparison with different chipless RFID designs.

\begin{tabular}{|c|c|c|c|c|c|c|}
\hline Resonator & $\begin{array}{c}\text { Frequency } \\
\text { Range } \\
\text { (GHz) }\end{array}$ & $\begin{array}{c}\text { Coding } \\
\text { Capacity } \\
\text { (bits) }\end{array}$ & $\begin{array}{c}\text { Coding } \\
\text { Density } \\
(\text { bits/cm²) }\end{array}$ & $\begin{array}{c}\text { Spectral } \\
\text { Capacity } \\
\text { (bits/GHz) }\end{array}$ & $\begin{array}{c}\text { Coding } \\
\text { Density } \\
\text { bits } /\left(\mathrm{GHz} \cdot \mathrm{cm}^{2}\right)\end{array}$ & $\begin{array}{l}\text { Read Range } \\
(\mathrm{cm})\end{array}$ \\
\hline Square loop [29] & $2-8$ & 5 & 1.23 & 0.83 & 0.21 & 55 \\
\hline Stepped impedance [27] & $3.1-10.6$ & NA & 7.9 & NA & NA & 50 \\
\hline U strips [6] & $7-12$ & 16 & 16.67 & 3.2 & 3.33 & 20 \\
\hline C-shaped [30] & $2-5$ & 15 & 1.25 & 5 & 0.416 & 80 \\
\hline U-folded dipoles [31] & $2-4$ & 20 & 0.77 & 10 & 0.385 & 25 \\
\hline Multiple L [23] & $3.1-10.6$ & 6 & 0.3 & 0.8 & 0.04 & 40 \\
\hline Plus loop [28] & $3.8-8.8$ & 20 & 1.25 & 4 & 0.25 & 25 \\
\hline L-shaped [19] & $4.8-10$ & 9 & 12 & 3.46 & 2.31 & 10 \\
\hline Proposed tag & $3-8$ & 20 & 15.15 & 4.44 & 3.37 & 60 \\
\hline
\end{tabular}

\section{Conclusions}

A novel and compact inverted-M chipless RFID tag was presented in this paper. The coding capacity was duplicated in the fixed operating bandwidth of $3 \mathrm{GHz}$ to $8 \mathrm{GHz}$ for the same tag size and the coding density was approximately $15.15 \mathrm{bits} / \mathrm{cm}^{2}$. Three prototypes were fabricated and tested outside the anechoic chamber environment with a fixed distance of $10 \mathrm{~cm}$ between the RFID reader and the tag being tested. Furthermore, an all-ones tag was tested at different distances from the reader $(10 \mathrm{~cm}, 30 \mathrm{~cm}$, and $60 \mathrm{~cm})$ and the measured results were compared. The simulated and measured results were in reasonable agreement, with an acceptable shift at some frequencies due to fabrication and experimental errors. The tag response was recognized even at a distance of $60 \mathrm{~cm}$.

Author Contributions: Conceptualization, K.I. and W.M.A.; methodology, W.M.A., A.-F.A.S., K.I., and S.A.A.; software, W.M.A. and K.I.; validation, W.M.A. and K.I.; formal analysis, W.M.A. and A.-F.A.S.; investigation, A.-F.A.S. and S.A.A.; resources, A.-F.A.S. and S.A.A.; data curation, W.M.A. and K.I.; writing-original draft preparation, W.M.A.; writing-review and editing, W.M.A., A.-F.A.S. and S.A.A.; visualization, W.M.A. and K.I.; supervision, A.-F.A.S. and S.A.A.

Funding: This research received no external funding.

Acknowledgments: The authors would like to thank Deanship of scientific research for funding and supporting this research through the initiative of DSR Graduate Students Research Support (GSR).

Conflicts of Interest: The authors declare no conflicts of interest.

\section{References}

1. Preradovic, S.; Karmakar, N.C. Multiresonator-Based Chipless RFID: Barcode of the Future; Springer Science \& Business Media: New York, NY, USA, 2012.

2. Pöpperl, M.; Parr, A.; Mandel, C.; Jakoby, R.; Vossiek, M. Potential and practical limits of time-domain reflectometry chipless RFID. IEEE Trans. Microw. Theory Tech. 2016, 64, 2968-2976. [CrossRef]

3. Herrojo, C.; Mata-Contreras, J.; Paredes, F.; Núñez, A.; Ramon, E.; Martín, F. Near-Field Chipless-RFID System With Erasable/Programmable 40-bit Tags Inkjet Printed on Paper Substrates. IEEE Microw. Wirel. Compon. Lett. 2018, 28, 272-274. [CrossRef]

4. Islam, M.A.; Karmakar, N. A compact printable dual-polarized chipless RFID tag using slot length variation in 'I' slot resonators. In Proceedings of the IEEE European Microwave Conference (EuMC), Paris, France, 7-10 September 2015.

5. Adbulkawi, W.M.; Sheta, A.A. A Compact Chipless RFID Tag Based on Frequency Signature. In Proceedings of the 9th IEEE-GCC Conference and Exhibition (GCCCE), Manamah, Bahrain, 8-11 May 2011.

6. Islam, M.A.; Karmakar, N.C. Real-World Implementation Challenges of a Novel Dual-Polarized Compact Printable Chipless RFID Tag. IEEE Trans. Microw. Theory Tech. 2015, 63, 4581-4591. [CrossRef]

7. Adbulkawi, W.M.; Sheta, A.-F.A. Printable Chipless RFID Tags for IoT Applications. In Proceedings of the 1st International Conference on Computer Applications \& Information Security (ICCAIS), Riyadh, Saudi Arabia, 4-6 April 2018. 
8. Balbin, I.; Karmakar, N.C. Phase-Encoded Chipless RFID Transponder for Large-Scale Low-Cost Applications. IEEE Microw. Wirel. Compon. Lett. 2009, 19, 509-511. [CrossRef]

9. Babaeian, F.; Karmakar, N.C. Hybrid Chipless RFID Tags-A Pathway to EPC Global Standard. IEEE Access 2018, 6, 67415-67426. [CrossRef]

10. Vena, A.; Perret, E.; Tedjini, S. Chipless RFID tag using hybrid coding technique. IEEE Trans. Microw. Theory Tech. 2011, 59, 3356-3364. [CrossRef]

11. Preradovic, S.; Karmakar, N.C. Chipless RFID: Barcode of the future. IEEE Microw. Mag. 2010, 7, 87-97. [CrossRef]

12. Abdulkawi, W.M.; Sheta, A.F.A. Multi-Resonator Structure for Small Size Chipless Radio Frequency Identification Tag. Int. J. Comput. Digit. Syst. 2018, 7, 43-49. [CrossRef]

13. Bhuiyan, M.S.; Karmakar, N.C. An efficient coplanar retransmission type chipless RFID tag based on dual-band McSrr. Prog. Electromagn. Res. 2014, 54, 133-141. [CrossRef]

14. Costa, F.; Genovesi, S.; Monorchio, A. Normalization-Free Chipless RFIDs by Using Dual-Polarized Interrogation. IEEE Trans. Microw. Theory Tech. 2016, 64, 310-318. [CrossRef]

15. Marindra, A.M.J.; Tian, G.Y. Chipless RFID Sensor Tag for Metal Crack Detection and Characterization. IEEE Trans. Microw. Theory Tech. 2018, 66, 2452-2462. [CrossRef]

16. Bibile, M.A.; Karmakar, N.C. Moving Chipless RFID Tag Detection Using Adaptive Wavelet-Based Detection Algorithm. IEEE Trans. Antennas Propag. 2018, 66, 2752-2760. [CrossRef]

17. Islam, M.A.; Karmakar, N.C. Compact Printable Chipless RFID Systems. IEEE Trans. Microw. Theory Tech. 2015, 63, 3785-3793. [CrossRef]

18. Islam, M.A.; Karmakar, N.C. A novel compact printable dual-polarized chipless RFID system. IEEE Trans. Microw. Theory Tech. 2012, 60, 2142-2151. [CrossRef]

19. Issa, K.; Ashraf, M.A.; AlShareef, M.R.; Behairy, H.; Alshebeili, S.; Fathallah, H. A Novel L-Shape Ultra Wideband Chipless Radio-Frequency Identification Tag. Int. J. Antennas Propag. 2017, 2017, 2823565. [CrossRef]

20. Huang, H.-F.; Su, L. A compact dual-polarized chipless RFID tag by using nested concentric square loops. IEEE Antennas Wirel. Propag. Lett. 2017, 16, 1036-1039. [CrossRef]

21. Islam, M.A.; Yap, Y.; Karmakar, N. ' $\Delta$ ' slotted compact printable orientation insensitive chipless RFID tag for long range applications. In Proceedings of the 2016 9th International Conference on Electrical and Computer Engineering (ICECE), Dhaka, Bangladesh, 20-22 December 2016.

22. Vena, A.; Perret, E.; Tedjini, S. High-capacity chipless RFID tag insensitive to the polarization. IEEE Trans. Antennas Propag. 2012, 60, 4509-4515. [CrossRef]

23. Laila, D.; Thomas, R.; Nijas, C.M.; Mohanan, P. A novel polarization independent chipless RFID tag using multiple resonators. Prog. Electromagn. Res. 2015, 55, 61-66. [CrossRef]

24. Dissanayake, T.; Esselle, K.P. Prediction of the Notch Frequency of Slot Loaded Printed UWB Antennas. IEEE Trans. Antennas Propag. 2007, 55, 3320-3325. [CrossRef]

25. Islam, M.A.; Karmakar, N. Design of a 16-bit ultra-low cost fully printable slot-loaded dual-polarized chipless RFID tag. In Proceedings of the Asia-Pacific Microwave Conference 2011, Melbourne, VIC, USA, 5-8 December 2011.

26. Khan, M.M.; Tahir, F.A.; Cheema, H.M. High capacity polarization sensitive chipless RFID tag. In Proceedings of the 2015 IEEE International Symposium on Antennas and Propagation \& USNC/URSI National Radio Science Meeting, Ancouver, BC, Canada, 19-24 July 2015.

27. Nijas, C.M.; Deepak, U.; Vinesh, P.V.; Sujith, R.; Mridula, S.; Vasudevan, K.; Mohanan, P. Low-cost multiple-bit encoded chipless RFID tag using stepped impedance resonator. IEEE Trans. Antennas Propag. 2014, 62, 4762-4770. [CrossRef]

28. Sajitha, V.R.; Nijas, C.M.; Roshna, T.K.; Vasudevan, K.; Mohanan, P. Compact cross loop resonator based chipless RFID tag with polarization insensitivity. Microw. Opt. Technol. Lett. 2016, 58, 944-947. [CrossRef]

29. Costa, F.; Genovesi, S.; Monorchio, A. A chipless RFID based on multiresonant high-impedance surfaces. IEEE Trans. Microw. Theory Tech. 2013, 61, 146-153. [CrossRef] 
30. Rance, O.; Siragusa, R.; Lemaitre-Auger, P.; Perret, E. Toward RCS magnitude level coding for chipless RFID. IEEE Trans. Microw. Theory Tech. 2016, 64, 2315-2325. [CrossRef]

31. Svanda, M.; Polivka, M.; Havlicek, J.; Machac, J. Chipless RFID tag with an improved magnitude and robustness of RCS response. Microw. Opt. Technol. Lett. 2017, 59, 488-492. [CrossRef]

(C) 2019 by the authors. Licensee MDPI, Basel, Switzerland. This article is an open access article distributed under the terms and conditions of the Creative Commons Attribution (CC BY) license (http://creativecommons.org/licenses/by/4.0/). 